\title{
Pengaruh Motivasi, Disiplin, Dan Lingkungan Kerja Terhadap Kinerja Karyawan PT. Romi Violeta Sidoarjo
}

\author{
Naila Amrillah Zakiah1, Jojok Dwiridotjahjono²
}

1,2 Program Studi Administrasi Bisnis, Universitas Pembangunan Nasional Veteran Jawa Timur, Surabaya

\begin{tabular}{|c|c|}
\hline INFO ARTIKEL & Abstract \\
\hline $\begin{array}{l}\text { Sejarah Artikel: } \\
\text { Diterima : } 2021 \\
\text { Diperbaiki : } 2021 \\
\text { Disetujui }: 2021\end{array}$ & \multirow{2}{*}{$\begin{array}{l}\text { Human resources are one of the factors that can affect the performance of a } \\
\text { company. Companies are required to manage human resources optimally to } \\
\text { achieve company goals. Employee performance is one of the benchmarks for } \\
\text { assessing the quality of human resources. } \\
\text { This study aims to determine: (1) The influence of work motivation on } \\
\text { employee performance of PT Romi Voleta Sidoarjo. (2) The influence of work } \\
\text { discipline on the employee performance of PT Romi Violeta Sidoarjo. (3) The } \\
\text { influence of the work environment on employee performance of PT. Romi } \\
\text { Violeta Sidoarjo. (4) The influence of work motivation, work discipline and } \\
\text { work environment on employee performance of PT Romi Violeta Sidoarjo. } \\
\text { This research uses quantitative methods. Using nonprobability sampling } \\
\text { technique. The sample of this study were } 135 \text { employees of PT Romi Violeta } \\
\text { Sidoarjo. Data collected using a questionnaire that had been tested for validity } \\
\text { and reliability. The data analysis technique used was multiple linear } \\
\text { regression. } \\
\text { Based on the results of data analysis, there is a simultaneous and partial } \\
\text { influence between the variables of motivation, discipline and work } \\
\text { environment on the performance of the employees of PT. Romi Violeta } \\
\text { Sidoarjo. }\end{array}$} \\
\hline $\begin{array}{l}\text { Keywords: } \\
\text { employee performance, work } \\
\text { discipline, work environment, work } \\
\text { motivation, }\end{array}$ & \\
\hline & Abstraks \\
\hline $\begin{array}{l}\text { Kata Kunci: } \\
\text { disiplin kerja, kine } \\
\text { lingkungan kerja, } \mathrm{m}\end{array}$ & \multirow[b]{2}{*}{$\begin{array}{l}\text { Sumber daya manusia merupakan salah satu faktor yang dapat } \\
\text { mempengaruhi kinerja suatu perusahaan. Perusahaan dituntut } \\
\text { mengelola sumber daya manusia secara maksimal untuk mencapai } \\
\text { tujuan perusahaan. Kinerja karyawan merupakan salah satu tolak ukur } \\
\text { untuk menilai kualitas sumber daya manusia. } \\
\text { Penelitian ini bertujuan untuk mengetahui : (1) Pengaruh motivasi } \\
\text { terhadap kinerja karyawan PT Romi Voleta Sidoarjo. (2) } \\
\text { Pengaruh disiplin terhadap kinerja karyawan PT Romi Violeta } \\
\text { Sidoarjo. (3) Pengaruh lingkungan kerja terhadap kinerja } \\
\text { karyawan PT. Romi Violeta Sidoarjo. (4) Pengaruh motivasi, disiplin } \\
\text { dan lingkungan kerja terhadap kinerja karyawan PT Romi Violeta } \\
\text { Sidoarjo. } \\
\text { Penelitian ini menggunakan metode kuantitatif. Teknik penarikan } \\
\text { sampel menggunakan nonprobability sampling. Sampel dari penelitian } \\
\text { ini sebanyak } 135 \text { orang karyawan PT Romi Violeta Sidoarjo. Data } \\
\text { dikumpulkan dengan kuesioner yang telah diuji validitas dan } \\
\text { reabilitasnya, teknik analisis data yang digunakan adalah regresi linier } \\
\text { berganda. } \\
\text { Berdasarkan hasil analisis data, terdapat pengaruh secara simultan dan } \\
\text { parsial antara variabel motivasi, disiplin dan lingkungan kerja } \\
\text { terhadap kinerja karyawan PT. Romi Violeta Sidoarjo. }\end{array}$} \\
\hline DOI: & \\
\hline
\end{tabular}




\section{PENDAHULUAN}

Saat ini persaingan perusahaan semakin kompetitif untuk memenangkan persaingan. Terdapat beberapa faktor yang dapat mempengaruhi suatu perusahaan dalam membangun, mengembangkan, dan meningkatkan kinerja perusahaan.

Salah satu faktor penting tersebut adalah sumber daya manusia. Sumber daya manusia merupakan asset penting dan berperan sebagai faktor penggerak utama dalam pelaksanaan seluruh kegiatan atau aktivitas organisasi. Jika manajemen sumber daya manusia dalam suatu perusahaan tidak berjalan baik maka akan berpengaruh terhadap kualitas sumber daya manusia yang terdapat dalam organisasi tersebut.

Kinerja karyawan merupakan salah satu tolak ukur yang dapat digunakan untuk menilai kualitas sumber daya manusia dalam suatu perusahaan. Hasil kerja secara kualitas dan kuantitas yang dicapai oleh seorang pegawai dalam melakukan tugasnya sesuai tanggung jawab yang diberikan kepadanya disebut kinerja karyawan. Makin baik kualitas atau banyak kuantitas dari pencapaian karyawan, berarti semakin baik kinerjanya.

Setiap perusahaan mengharapkan agar pegawainya dapat memiliki kinerja yang baik. informasi mengenai kinerja karyawan dapat diketahui dari penilaian kinerja. Berikut data penilaian kerja karyawan pada PT Romi Violeta Sidoarjo :

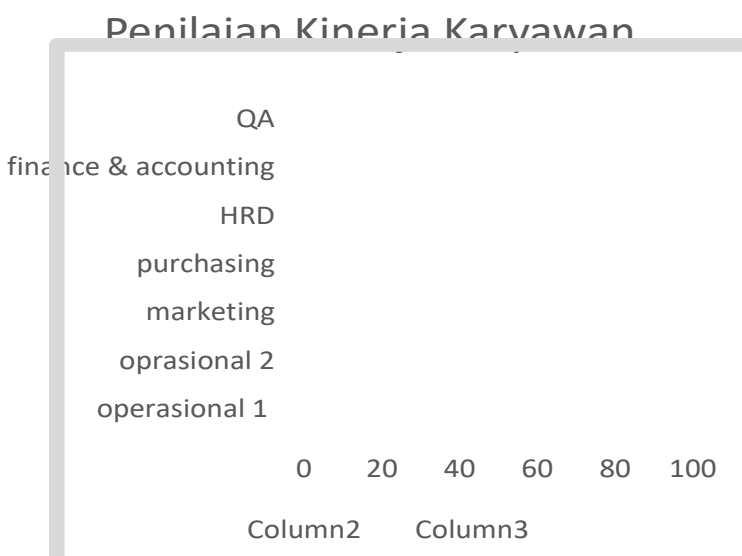

Gambar 1. Penilaian Kinerja Karyawan PT Romi Violeta Sidoarjo Bulan Januari - Desember 2020

Berdasarkan gambar diatas, dapat diketahui bahwa devisi marketing yang memiliki nilai tertinggi atau yang paling baik sehingga mampu memberikan hasil yang memuaskan, sedangkan devisi purchasing (pembelian) memberikan hasil yang kurang baik dan optimal sehingga mendapatkan nilai yang rendah. Dari hasil tersebut menunjukkan bahwa terdapat permasalahan dalam kinerja karyawan yang belum sesuai dengan harapan.

Untuk mengatasi permasalahan kinerja karyawan yang dihadapi perusahaan, diperlukan upaya-upaya untuk meningkatkan kinerja karyawan. Menurut Kasmir (2016) motivasi kerja, disiplin kerja, dan motivasi kerja merupakan beberapa faktor yang mempengaruhi kinerja karyawan.

Menurut Prabu \& Wijayanti (2016) karyawan yang termotivasi akan lebih produktif serta semakin bersemangat untuk bekerja untuk mencapai tujuan perusahaan daripada karyawan yang memiliki pengalaman motivasi yang rendah. Dengan kinerja tinggi mereka akan mengarahkan sebuah perusahaan ke arah tujuan yang lebih baik.

Motivasi kerja sangat erat kaitannya dengan perkembangan disiplin dalam bekerja. Tindakan pendisiplinan memang harus tegas dalam pelaksanaanya. Meskipun perusahaan ingin agar keinginan karyawan dapat terintegrasikan atau terlaksana sesuai dengan tujuan perusahaan, karyawan juga harus mencoba memahami berbagai tingkah laku manusia, bukan berarti manajemen harus mengikuti kehendak karyawan. Selama perusahaan sudah mempunyai peraturan dan telah disetujui secara bersama maka pelanggaran terhadap peraturan harus dikenakan tindakan kedisiplinan.

Menurut Hamali (2018) disiplin kerja dapat dipandang sebagai sesuatu yang mempunyai manfaat yang besar, baik dalam kepentingan organisasi maupun bagi karyawan. Menjamin terpeliharanya tata tertib dan kelancaran pelaksanaan tugas, hingga memperoleh hasil yang optimal, adalah manfaat disiplin kerja bagi organisasi, sedangkan bagi karyawan mampu melakukan tugasnya dengan penuh kesadaran dan dapat menambah semangat dalam melaksanakan pekerjaannya.

Faktor lain yang juga dapat mempengaruhi kinerja karyawan adalah lingkungan kerja yang kondusif bagi karyawan yang bekerja dalam 
perusahaan. Lingkungan kerja dalam suatu perusahaan sangatlah penting diperhatikan oleh manajemen. Lingkungan kerja yang nyaman bagi karyawan, dapat meningkatkan kinerja karyawan. Sebaliknya, jika lingkungan kerja yang diciptakan perusahaan tidak sesuai dan tidak memadai akan dapat menurunkan kinerja karyawan.

Penelitian ini menganalisis seberapa besar pengaruh motivasi, disiplin, dan lingkungan kerja terhadap kinerja karyawan pada PT Romi Violeta Sidoarjo, baik secara parsial maupun simultan. Penelitian ini diharapkan dapat memberi masukan bagi perusahaan yaitu PT Romi Violeta Sidoarjo agar dapat mempertahankan dan meningkatkan kinerja karyawan, serta pengembangan dalam bidang sumber daya manusia.

\section{TINJAUAN PUSTAKA \\ Kinerja Karyawan}

Menurut Ansory \& Indrasari (2018) kinerja karyawan merupakan hasil kerja secara kualitas dan kuantitas yang dicapai oleh seseorang pegawai dalam melaksanakan tugasnya dengan tanggung jawab yang diberikan kepadanya, pelaksanaan pekerjaan akan lebih efektif apabila didukung dengan keyakinan dan motivasi yang tinggi.

Menurut Hamali (2018), kinerja merupakan hasil pekerjaan yang mempunyai hubungan kuat dengan tujuan strategis organisasi, kepuasan konsumen, dan memberikan kontribusi pada ekonomi.

Penilaian kinerja merupakan salah satu fungsi dari manajemen sumber daya manusia, maka sudh kewajibannya untuk dijalankan dengan sebaik-baiknya. Dengan adanya penilaian kinerja manajemen dapat menentukan kesejahteraan yang pantas diberikan kepada karyawannya (Kasmir, 2016).

Menurut Kasmir (2016) motivasi kerja, disiplin kerja, dan motivasi kerja merupakan beberapa faktor yang mempengaruhi kinerja karyawan.

\section{Motivasi}

Menurut Rivai (2013) motivasi adalah serangkaian sikap dan nilai-nilai yang mempengaruhi seseorang untuk mencapai hal-hal yang spesifik sesuai dengan tujuan individu.

Menurut Hasibuan (2017) motivasi adalah pemberian daya penggerak yang menciptakan kegairahan kerja seseorang, agar mereka mau bekerja sama, bekerja drivtif, dan berintegrasi dengan segala upayanya untuk mencapai kepuasan.

Menurut Sutrisno (2017) motivasi dipengaruhi oleh faktor intern dan faktor ekstern. Faktor intern terdiri dari: keinginan untuk dapat hidup, keinginan untuk memperoleh penghargaan, keinginan untuk dapat memiliki, keinginan untuk memperoleh pengakuan, keinginan untuk berkuasa. Faktor ekstern terdiri dari : kondisi lingkungan kerja yang baik, kompensasi yang memadai, adanya jaminan pekerjaan, peraturan yang fleksibel, status dan tanggung jawab.

Menurut Hasibuan (2017), ada lima jenjang kebutuhan dalam diri manusia, yaitu physiological needs, safety and security needs, affiliation or acceptance needs, esteem or status needs, dan self actualization.

Menurut Sutrisno (2017), motivasi mendorong gairah karyawan untuk bekerja keras dengan memberikan semua kemampuan dan keterampilan yang dimiliki demi mewujudkan tujuan perusahaan. Motivasi karyawan yang baik terhadap perusahaan akan meningkatkan kualitas kinerja karyawan.

Berdasarkan hasil penelitian yang dilakukan oleh Hustia (2020), Daspar (2020), Mutmainah (2017), dan Aini \& Ariefiantoro (2019) menyatakan bahwa motivasi berpengaruh signifikan terhadap kinerja karyawan.

\section{Disiplin Kerja}

Menurut Hasibuan (2017), disiplin merupakan kesadaran dan kesediaan seseorang menaati semua peraturan perusahaan dan norma-norma sosial yang berlaku. Sikap seseorang yang secara sukarela menaati peraturan dan sadar akan tugas dan tanggung jawabnya disebut kesadaran. Sedangkan suatu sikap, tingkah laku, dan perubatan seseorang yang sesuai dengan peraturan perusahaan, baik yang tertulis manupun tidak disebut kesediaan.

Untuk meningkatkan prestasi kerja, diperlukan suatu bentuk pelatihan yang berusaha memperbaiki dan membentuk pengetahuan, sikap dan perilaku karyawan yang dapat disebut disiplin (Siagian, 2015).

Berdasarkan hasil penelitian yang dilakukan oleh Hustia (2020), Daspar (2020), Mutmainah (2017), dan Aini \& Ariefiantoro (2019) menyatakan bahwa disiplin berpengaruh signifikan terhadap kinerja karyawan.

\section{Lingkungan Kerja}

Lingkungan kerja adalah lingkungan dimana pegawai melakukan pekerjaannya sehari-hari. Menurut (Rivai, 2013) lingkungan kerja adalah keseluruhan sarana dan prasarana yang ada di sekitar karyawan yang sedang melakukan pekerjaan itu sendiri. Lingkungan kerja ini akan meliputi tempat kerja, fasilitas, dan alat bantu kerja, 
kebersihan, pencahayaan, dan ketenangan.

Diperlukan beberapa hal untuk menciptakan lingkungan kerja yang baik, yaitu : (1) ruangan kerja yang lega, (2) ventilasi pertukaran udara, (3) tersedianya tempat-tempat ibadah keagamaan, (4) tersedianya sarana khusus maupun umum untuk karyawan yang nyaman dan mudah, (5) hubungan antara karyawan dengan sesama karyawan lain terjalin secara harmonis, (6) hubungan antara karyawan dan pimpinan terjalin dengan baik.

Lingkungan kerja yang kondusif akan membawa dampak baik bagi kelangsungan kinerja karyawan, sehingga lingkungan kerja berkontribusi dalam meningkatkan kinerja karyawan dalam suatu perusahaan.

Berdasarkan hasil penelitian yang dilakukan oleh Hustia (2020), Daspar (2020), Mutmainah (2017), dan Aini \& Ariefiantoro (2019) menyatakan bahwa lingkungan kerja berpengaruh signifikan terhadap kinerja karyawan.

\section{Kerangka Berpikir}

Berdasarkan penjelasan yang dibahas dalam kajian pustaka, berikut adalah kerangka berpikir dalam penelitian ini :

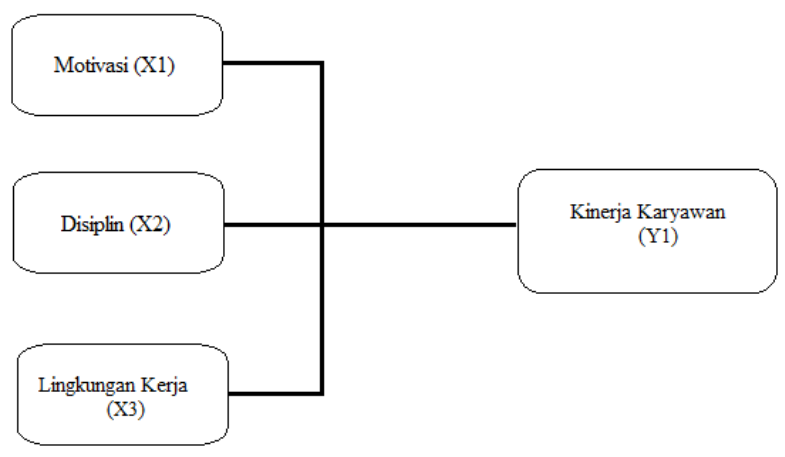

Gambar 1. Kerangka Berpikir

Sumber : Data Diolah Peneliti (2021)

Hipotesis

Berikut hipotesis dalam penelitian ini:

H1 : terdapat pengaruh secara simultan pada motivasi, disiplin kerja dan lingkungan kerja terhadap kinerja karyawan pada PT. Romi Violeta. $\mathrm{H} 2$ : terdapat pengaruh secara parsial pada motivasi terhadap kinerja karyawan pada PT. Romi Violeta.

H3 : terdapat pengaruh secara parsial pada disiplin kerja terhadap kinerja karyawan pada PT. Romi Violeta.

H4 : terdapat pengaruh secara parsial pada lingkungan kerja terhadap kinerja karyawan pada PT. Romi Violeta

\section{METODE PENELITIAN \\ Pendekatan Penelitian}

Penelitian ini menggunakan metode kuantitatif. Metode kuantitatif merupakan penelitian yang menggunakan analisis data yang berbentuk angka (Suryani \& Hendrayadi, 2015).

\section{Jenis dan Sumber Data}

Jenis data yang digunakan adalah data primer, yaitu data yang dikumpulkan secara langsung atau data yang masih asli seperti apa adanya (Tarjo, 2019). Sumber data berasal dari data internal., yaitu data diperoleh dari dalam perusahaan PT Romi Violeta Sidoarjo.

\section{Teknik Pengumpulan Data}

Pengumpulan data menggunakan kuesioner. Kuesioner merupakan teknik pengumpulan data yang dilakukan dengan cara memberi seperangkat pernyataan tertulis kepada responden untuk dijawabnya (Sugiyono, 2017). Responden dalam penelitian ini adalah 135 orang karyawan PT Romi Violeta Sidoarjo.

\section{Teknik Analisis Data}

Teknik analisis data menggunakan regresi linier berganda, yaitu untuk menganalisis besarnya pengaruh variabel dependen pada variabel independen (Purnomo, 2016). Data diolah menggunakan perangkat lunak SPSS.

\section{Pengukuran Variabel}

Skala pengukuran menggunakan skala likert dengan 5 tingkatan. Skala likert digunakan untuk mengukur sikap, pendapat, dan persepsi seseorang atau kelompok tentang fenomena sosial (Sugiyono, 2017).

\section{Sampel Penelitian}

Sampel penelitian ini adalah 135 karyawan PT Romi Violeta Sidoarjo

\section{HASIL PENELITIAN}

Gambaran Umum Responden

Tabel 1. Gambaran Umum Responden

\begin{tabular}{ccc}
\hline Jenis Kelamin & Jumlah (orang) & Presentase \\
\hline Laki-laki & 63 & $46,7 \%$ \\
Perempuan & 72 & $53,3 \%$ \\
\hline Pendidikan & Jumlah (orang) & Presentase \\
Terakhir & & \\
\hline SMA/SMK & 45 & $33,3 \%$ \\
Diploma & 35 & $25,9 \%$ \\
S1 & 53 & $39,3 \%$ \\
S2 & 2 & $1,5 \%$ \\
\hline Usia & Jumlah (orang) & Presentase \\
\hline 18 - 25 tahun & 29 & $21,5 \%$ \\
$26-30$ tahun & 35 & $25,9 \%$ \\
$31-35$ tahun & 51 & $37,8 \%$ \\
Lebih dari 35 & 20 & $14,8 \%$ \\
tahun & & \\
\hline
\end{tabular}

Sumber : Data Diolah Peneliti (2021) 
Berdasarkan tabel di atas dapat diketahui bahwa responden berjenis kelamin perempuan sebesar $53,3 \%$ dan yang berjenis kelamin laki-laki $46,7 \%$. Lalu berdasarkan pendidikan terakhir, paling banyak responden adalah lulusan S1 $(39,3 \%)$, yang kedua adalah lulusan SMA/SMK $(33,3 \%)$, lalu Diploma $(25,9 \%)$ dan S2 $(1,5 \%)$.

\section{Uji Validitas}

Pengukuran validitas dilakukan dengan cara menghitung korelasi antara skor masing-masing item dengan skor total menggunakan teknik korelasi product moment. Jika nilai korelasi (r) lebih besar dari $r$ tabel, maka suatu indikator dapat dikatakan valid. Berikut hasil uji validitas.

Tabel 2. Uji Validitas

\begin{tabular}{cccc}
\hline Indikator & Korelasi $(\mathrm{r})$ & Kondisi & Keterangan \\
\hline X.1.1 & 0,538 & $\mathrm{r}>0,169$ & Valid \\
X.1.2 & 0,610 & $\mathrm{r}>0,169$ & Valid \\
X.1.3 & 0,727 & $\mathrm{r}>0,169$ & Valid \\
X.1.4 & 0,592 & $\mathrm{r}>0,169$ & Valid \\
X.1.5 & 0,697 & $\mathrm{r}>0,169$ & Valid \\
\hline X.2.1 & 0,769 & $\mathrm{r}>0,169$ & Valid \\
X.2.2 & 0,711 & $\mathrm{r}>0,169$ & Valid \\
X.2.3 & 0,747 & $\mathrm{r}>0,169$ & Valid \\
X.2.4 & 0,744 & $\mathrm{r}>0,169$ & Valid \\
X.2.5 & 0,646 & $\mathrm{r}>0,169$ & Valid \\
X.2.6 & 0,783 & $\mathrm{r}>0,169$ & Valid \\
X.2.7 & 0,760 & $\mathrm{r}>0,169$ & Valid \\
\hline X.3.1 & 0,622 & $\mathrm{r}>0,169$ & Valid \\
X.3.2 & 0,760 & $\mathrm{r}>0,169$ & Valid \\
X.3.3 & 0,798 & $\mathrm{r}>0,169$ & Valid \\
X.3.4 & 0,605 & $\mathrm{r}>0,169$ & Valid \\
X.3.5 & 0,787 & $\mathrm{r}>0,169$ & Valid \\
X.3.6 & 0,727 & $\mathrm{r}>0,169$ & Valid \\
\hline Y.1 & 0,493 & $\mathrm{r}>0,169$ & Valid \\
Y.2 & 0,677 & $\mathrm{r}>0,169$ & Valid \\
Y.3 & 0,748 & $\mathrm{r}>0,169$ & Valid \\
Y.4 & 0,668 & $\mathrm{r}>0,169$ & Valid \\
Y.5 & 0,613 & $\mathrm{r}>0,169$ & Valid \\
\hline S.
\end{tabular}

Sumber : Data Diolah Peneliti (2021)

\section{Uji Reliabilitas}

Reliabilitas merupakan indeks yang menunjukkan sejauh mana suatu alat ukur dipakai dua kali untuk mengukur gejala yang sama dan hasil pengukurannya relatif sama maka alat ukur tersebut reliabel. Jika nilai alpha melebihi 0,6 maka pernyataan pada indikator variabel dikatakan reliabel.
Tabel 3. Uji Reliabilitas

\begin{tabular}{cccl}
\hline Variabel & $\begin{array}{c}\text { Nilai } \\
\text { Alpha (a) }\end{array}$ & Kondisi & Keterangan \\
\hline $\begin{array}{c}\text { Motivasi Kerja } \\
(X 1)\end{array}$ & 0,627 & $\mathrm{a}>0,6$ & Reliabel \\
$\begin{array}{c}\text { Disiplin Kerja } \\
(X 2)\end{array}$ & 0,866 & $\mathrm{a}>0,6$ & Reliabel \\
$\begin{array}{c}\text { Lingkungan } \\
\text { Kerja (X3) } \\
\text { Kinerja }\end{array}$ & 0,811 & $\mathrm{a}>0,6$ & Reliabel \\
Karyawan (Y) & 0,637 & $\mathrm{a}>0,6$ & Reliabel \\
\hline
\end{tabular}

Sumber : Data Diolah Peneliti (2021)

\section{Uji Analisis Regresi Linier Berganda}

Berikut hasil perhitungan regresi dengan bantuan program SPSS 2.0 :

Tabel 4. Uji Regresi

\begin{tabular}{ccc}
\hline \multirow{2}{*}{ Model } & \multicolumn{2}{c}{ Unstandardized Coefficients } \\
\cline { 2 - 3 } & $\mathrm{B}$ & Std. Error \\
\hline (Constant) & 0,940 & 0,212 \\
Motivasi Kerja (X1) & 0175 & 0,064 \\
Disiplin Kerja (X2) & 0,272 & 0,081 \\
Lingkungan Kerja (X3) & 0,356 & 0,079 \\
\hline Sumber : Data Diolah Peneliti (2021) \\
Berdasarkan tabel diatas, maka persamaan regresi \\
yang terbentuk pada uji regresi ini adalah : \\
Y= a + b1X1 + b2X2 + b3X3 \\
Y=0,940 + 0,175 X1 + 0,272 X2 + 0,356 X3 \\
Sehingga dapat diinterpretasikan sebagai berikut :
\end{tabular}

a. Konstanta (a) sebesar 0,940 yaitu apabila variabel bebas Motivasi dan Disiplin, Lingkungan Kerja bernilai konstan, maka besarnya variabel terikat kinerja karyawan sebesar 0,940 satuan.

b. Motivasi (X1) memiliki nilai koefisien sebesar 0,175 . Berarti koefisien variabel Motivasi (X1) memiliki pengaruh positif (searah) terhadap Kinerja Karyawan (Y). Apabila Motivasi bertambah satu satuan, maka kinerja karyawan akan bertambah sebesar 0,175 satuan. Artinya semakin tinggi tingkat Motivasi maka semakin tinggi kinerja karyawan PT. Romi Violeta Sidoarjo.

c. Disiplin (X2) memiliki nilai koefisien sebesar 0,272 . Berarti koefisien variabel Disiplin $(X 2)$ memiliki pengaruh positif (searah) terhadap Kinerja Karyawan (Y). Apabila faktor Disiplin bertambah satu satuan, maka kinerja karyawan akan bertambah sebesar 0,272 satuan. Artinya semakin bertambahnya faktor Disiplin, maka semakin tinggi Kinerja Karyawan PT. Romi Violeta Sidoarjo.

d. Lingkungan Kerja (X3) memiliki nilai koefisien 
sebesar 0,356. Berarti koefisien variabel Lingkungan Kerja (X3) memiliki pengaruh positif (searah) terhadap Kinerja Karyawan (Y). Apabila faktor Lingkungan Kerja bertambah satu satuan, maka kinerja karyawan akan bertambah sebesar 0,356 satuan. Artinya semakin bertambahnya faktor Lingkungan Kerja, maka semakin tinggi Kinerja Karyawan PT. Romi Violeta Sidoarjo.

\section{Uji Asumsi Klasik}

Uji Normalitas

Berdasarkan hasil uji normalitas menggunakan uji Kolmogorov-Smirnov dihasilkan nilai probabilitas lebih dari 0,05 yaitu 0,530. Sehingga model regresi memenuhi asumsi normalitas.

\section{Uji Multikolinieritas}

Uji multikolinieritas dapat dilihat berdasarkan nilai Variance Inflation Factor (VIF). Jika nilai VIF per-variabel bebas lebih kecil dari 10 dan nilai tolerance lebih besar dari 0,10 maka tidak terjadi multikolinieritas.

Tabel 5. Uji Multikolinieritas

\begin{tabular}{|c|c|c|c|}
\hline Variabel & Tolerance & VIF & Keterangan \\
\hline $\begin{array}{c}\text { Motivasi Kerja } \\
(\mathrm{X} 1)\end{array}$ & 0,495 & 2,022 & $\begin{array}{c}\text { Bebas } \\
\text { Multikolinieritas }\end{array}$ \\
\hline $\begin{array}{c}\text { Disiplin Kerja } \\
(\mathrm{X} 2)\end{array}$ & 0,222 & 4,510 & $\begin{array}{c}\text { Bebas } \\
\text { Multikolinieritas }\end{array}$ \\
\hline $\begin{array}{l}\text { Lingkungan } \\
\text { Kerja (X3) }\end{array}$ & 0,253 & 3,955 & $\begin{array}{c}\text { Bebas } \\
\text { Multikolinieritas }\end{array}$ \\
\hline
\end{tabular}

Sumber : Data Diolah Peneliti (2021)

\section{Uji Autokorelasi}

Berdasarkan hasil uji autokorelasi menggunakan uji Durbin-Watson diperoleh hasil 1,987. Nilai ini terletak pada daerah -2 dan +2 , sehingga dapat disimpulkan bahwa regresi bebas dari autokorelasi.

\section{Uji Heterokedastisitas}

Berikut hasil uji heterokedastisitas menggunakan grafik scatterplot :

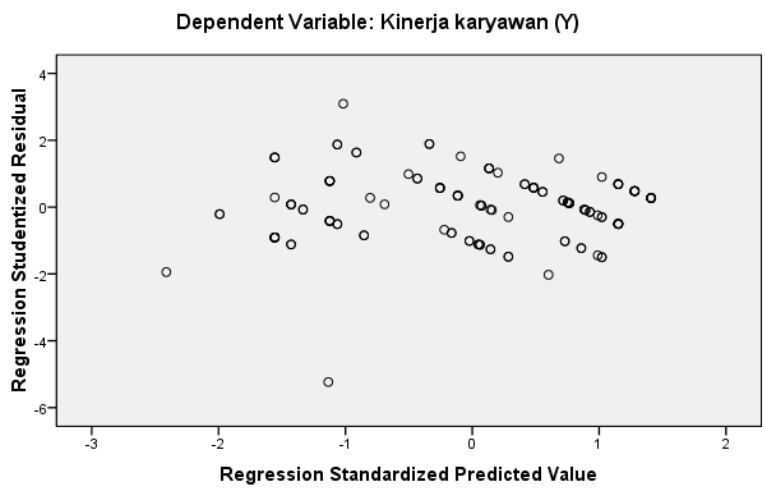

Gambar 2. Grafik Scatterplot

Sumber : Hasil Olah Data SPSS (2021)

Pada gambar diatas, grafik plot tidak membentuk pola tertentu yang teratur sehingga tidak terjadi heterokedastisitas.

Uji Hipotesis

Uji Signifikansi Simultan (Uji-F)

Berikut hasil analisis uji-F dengan bantuan program SPSS :

Tabel 6. Uji F

\begin{tabular}{|c|c|c|c|c|c|c|}
\hline \multicolumn{7}{|c|}{ ANOVA $^{\mathrm{b}}$} \\
\hline \multicolumn{2}{|c|}{ Model } & $\begin{array}{l}\text { Sum of } \\
\text { Squares }\end{array}$ & Df & $\begin{array}{l}\text { Mean } \\
\text { Square }\end{array}$ & $\mathrm{F}$ & Sig. \\
\hline 1 & Regression & 9.817 & 3 & 3.272 & 113.787 & $.000^{\mathrm{a}}$ \\
\hline & Residual & 3.767 & 131 & .029 & & \\
\hline & Total & 130.584 & 134 & & & \\
\hline
\end{tabular}

a. Predictors: (Constant), Lingkungan kerja (X3), Motivasi (X1), Disiplin (X2)

b. Dependent Variable : Kinerja Karyawan (Y)

Sumber : Hasil Olah Data SPSS (2021)

Hasil pengujian model secara bersama-sama (simultan) di atas diperoleh nilai Fhitung sebesar 113,787 lebih besar dari nilai Ftabel sebesar 2,674, dan menghasilkan nilai signifikansi sebesar 0,000 yang jauh lebih kecil dari nilai signifikansi $a=5 \%$ atau 0,05. Sehingga H0 ditolak dan H1 diterima. Artinya bahwa variabel Motivasi, Disiplin, dan Lingkungan Kerja secara bersama-sama (simultan) memiliki pengaruh yang signifikan terhadap variabel Kinerja Karyawan pada PT. Romi Violeta Sidoarjo.

\section{Uji Signifikansi Parsial (Uji-t)}

Berikut hasil analisis uji-t dengan program SPSS :

Tabel 5. Uji t

\begin{tabular}{|c|c|c|}
\hline Model & $\mathrm{T}$ & Sig. \\
\hline Motivasi (X1) & 2.724 & .007 \\
\hline Disiplin (X2) & 3.356 & .001 \\
\hline $\begin{array}{l}\text { Lingkungan Kerja } \\
\text { (X3) }\end{array}$ & 4.519 & .000 \\
\hline
\end{tabular}

Sumber : Hasil Olah Data SPSS (2021)

Dari tabel diatas dapat disimpulkan bahwa :

1. H0 ditolak dan H2 diterima, Motivasi (X1) berpengaruh signifikan terhadap Kinerja Karyawan (Y) pada PT. Romi Violeta Sidoarjo. Dengan nilai thitung sebesar 2,724 lebih besar dari nilai ttabel sebesar 1,657, dan nilai signifikansi yang dihasilkan sebesar 0,007 lebih kecil dari nilai signifikansi yang digunakan yaitu a $5 \%$ atau 0,05 .

2. H0 ditolak dan H3 diterima, Disiplin (X2) berpengaruh signifikan terhadap Kinerja Karyawan (Y) pada PT. Romi Violeta Sidoarjo. Dengan nilai thitung sebesar 3,356 lebih besar dari nilai ttabel sebesar 1,657, dan nilai signifikansi yang dihasilkan sebesar 0,001 
lebih kecil dari nilai signifikansi yang digunakan yaitu a $5 \%$ atau 0,05 .

3. H0 ditolak dan H4 diterima, Lingkungan Kerja (X3) berpengaruh signifikan terhadap Kinerja Karyawan (Y) pada PT. Romi Violeta Sidoarjo. Dengan nilai thitung sebesar 4,519 lebih besar dari nilai ttabel sebesar 1,657, dan nilai signifikansi yang dihasilkan sebesar 0,000 lebih kecil dari nilai signifikansi yang digunakan yaitu a $5 \%$ atau 0,05 .

\section{Koefisien Determinan $\left(\mathbf{R}^{2}\right)$}

Berikut hasil analisis koefisien determinan dengan bantuan SPSS :

Tabel 5. Koefisien Determinan

\begin{tabular}{|l|c|r|r|r|}
\hline Model & $\mathrm{R}$ & $\begin{array}{c}\mathrm{R} \\
\text { Square }\end{array}$ & $\begin{array}{r}\text { Adjusted } \\
\mathrm{R} \text { Square }\end{array}$ & $\begin{array}{c}\text { Std. Error of } \\
\text { the Estimate }\end{array}$ \\
\hline 1 & .850 & .723 & .716 & .16958 \\
\hline
\end{tabular}

Sumber : Hasil Olah Data SPSS (2021)

Hasil analisis data didapatkan nilai koefisien determinasi yang telah disesuaikan (Adjusted $\mathrm{R}$ square) sebesar 0,716 atau sebesar $71,6 \%$. Artinya bahwa variabel bebas mempunyai pengaruh terhadap variabel terikat sebesar $71,6 \%$, sedangkan sisanya sebesar $(100 \%-71,6 \%=28,4 \%)$ dipengaruhi oleh variabel lain di luar variabel penelitian ini.

\section{PEMBAHASAN}

Berdasarkan hasil analisis data yang telah dilakukan dapat diketahui bahwa motivasi, disiplin, dan lingkungan kerja berpengaruh positif dan signifikan terhadap kinerja karyawan PT. Romi Violeta Sidoarjo, baik secara parsial maupun secara simultan. Dari hasil uji determinasi dapat diketahui bahwa motivasi, disiplin, dan lingkungan kerja memiliki kontribusi sebesar 71,6\% mempengaruhi kinerja karyawan pada PT Romi Violeta Sidoarjo.

Dari hasil analisis linier berganda, dapat diketahui bahwa lingkungan kerja memiliki pengaruh paling besar terhadap kinerja karyawan. Sehingga PT Romi Violeta Sidoarjo perlu lebih memperhatikan faktor lingkungan kerja, yaitu mempertahankan lingkungan kerja yang kondusif. PT Romi Violeta Sidoarjo juga harus memperhatikan motivasi dan disiplin kerja untuk mempertahankan dan meningkatkan kinerja karyawan. Dengan kinerja karyawan yang baik, dapat meningkatkan kinerja perusahaan agar memiliki daya saing yang kuat antar perusahaan.

Penjelasan dari hasil-hasil tersebut sejalan dengan teori (Kasmir, 2016) yang menyatakan bahwa motivasi kerja, lingkungan kerja, dan disiplin kerja merupakan beberapa faktor yang mempengaruhi kinerja karyawan. Hasil penelitian ini sejalan dengan penelitian terdahulu yang dilakukan oleh Hustia (2020), Mutmainah (2017), Aini \& Ariefiantoro (2019), yang menyatakan bahwa terdapat pengaruh signifikan pada motivasi, disiplin, dan lingkungan kerja terhadap kinerja karyawan, secara simultan dan secara parsial.

Hasil penelitian ini juga sejalan dengan penelitian yang dilakukan oleh Daspar (2020) yaitu lingkungan kerja memiliki pengaruh terbesar dibanding dengan faktor disiplin, dan lingkungan kerja.

Terdapat perbedaan hasil pada penelitian ini terhadap penelitian terdahulu, yaitu pada penelitian yang dilakukan oleh Aini \& Ariefiantoro (2019) dan Mutmainah (2017) menyatakan bahwa motivasi memiliki pengaruh lebih dominan dibandingkan disiplin dan lingkungan kerja, pada penelitian yang dilakukan oleh Hustia (2020) menyatakan bahwa disiplin kerja memiliki pengaruh lebih dominan dibandingkan dengan variabel dalam penelitiannya yaitu motivasi dan lingkungan kerja, dan pada penelitian yang dilakukan oleh Daspar (2020) menyatakan bahwa motivasi berpengaruh tidak signifikan terhadap kinerja karyawan.

\section{SIMPULAN DAN SARAN}

Berdasarkan hasil analisis data yang telah dilakukan dapat disimpulkan bahwa terdapat pengaruh positif dan signifikan pada motivasi, disiplin, dan lingkungan kerja terhadap kinerja karyawan PT Romi Violeta Sidoarjo, baik secara simultan maupun secara parsial. Variabel yang paling berpengaruh terhadap kinerja karyawan adalah variabel Lingkungan Kerja. Berdasarkan hasil analisis data, perusahaan disarankan untuk terus memperhatikan motivasi, disiplin, dan lingkungan kerja untuk mempertahankan serta meningkatkan kinerja karyawan.

\section{DAFTAR PUSTAKA}

Aini, K. N., \& Ariefiantoro, T. (2019). Pengaruh Motivasi, Lingkungan Kerja, Dan Disiplin Kerja Terhadap Kinerja Karyawan PT. Perkebunan Nusantara IX Semarang (Studi Pada Karyawan Bagian Produksi Karet Kebun Sukamangli di PT. Perkebunan Nusantara IX Semarang). Solusi, $16(4)$. https://doi.org/10.26623/slsi.v16i4.1672

Ansory, A. F., \& Indrasari, M. (2018). Manajemen Sumber Daya Manusia - Edisi Pertama. 
Indomedia Pustaka.

Daspar, D. (2020). Pengaruh Lingkungan, Motivasi dan Disiplin Kerja Terhadap Kinerja Karyawan. EKOMABIS: Jurnal Ekonomi Manajemen Bisnis, 1(02), 159-166. https://doi.org/10.37366/ekomabis.v1i02.31

Hamali, A. Y. (2018). Pemahaman Manajemen Sumber Daya Manusia. CAPS (Center for Academic Publishing).

Hasibuan, M. S. . (2017). Manajemen Sumber Daya Manusia Edisi Revisi. Bumi Aksara.

Hustia, A. (2020). Pengaruh Motivasi Kerja, Lingkungan Kerja Dan Disiplin Kerja Terhadap Kinerja Karyawan Pada Perusahaan WFO Masa Pandemi. Jurnal Ilmu Manajemen, 10(1),

81. https://doi.org/10.32502/jimn.v10i1.2929

Kasmir. (2016). Manajemen Sumber Daya Manusia Teori dan Aplikasi. Raja Grafindo Persada.

Mutmainah, N. (2017). Pengaruh motivasi, lingkungan kerja, disiplin kerja dan kompensasi kerja terhadap kinerja karyawan Bank BNI Syariah KC Semarang. IAIN SALATIGA, 1-119. http://erepository.perpus.iainsalatiga.ac.id/2765/1/S KRIPSI NEW.pdf

Prabu, A. S., \& Wijayanti, D. T. (2016). Pengaruh Penghargaan dan Motivasi Terhadap Kinerja Karyawan (Studi Pada Divisi Penjualan PT. United Motors Center Suzuki Ahmad Yani, Surabaya). Jurnal Ekonomi Bisnis Dan Kewirausahaan, 5(2). https://doi.org/10.26418/jebik.v5i2.17144

Purnomo, R. A. (2016). Analisis Statistik Ekonomi dan Bisnis dengan SPSS (Cetakan ke). CV. Wade Group.

Rivai, V. (2013). Manajemen Sumber Daya Manusia Untuk Perusahaan Dari Teori Ke Praktik. Raja Grafindo Persada.

Siagian, S. (2015). Manajemen Sumber Daya Manusia. Bumi Aksara.

Sugiyono. (2017). MetodePenelitian Kuantitatif, Kualitatif dan RED. Bandung: PT Alfabet. PT Alfabet.

Suryani, \& Hendrayadi. (2015). Metode Riset Kuantitatif. K prenadamedia grup.

Sutrisno, E. (2017). Manajemen Sumber Daya Manusia. Kencana.

Tarjo. (2019). Metode Penelitian. Deepublish Publisher. 